\title{
Design of a Single Stage Transformerless VSI in a Smart Microgrid for PV-STATCOM/ESS operations
}

\author{
Fida Hasan Md Rafi, M. J. Hossain, J. Lu \\ Queensland Micro and Nanotechnology Center, School of Engineering, Griffith University, Gold Coast 4222, Australia \\ fida.rafi@griffithuni.edu.au,j.hossain@griffith.edu.au,j.lu@griffith.edu.au
}

\begin{abstract}
In recent years, the microgrid has emerged as a promising concept and gained significant attention along with different renewable energy sources in the distribution network. Proper power coordination and strategic controller selection can extend the horizon of applications of the traditional microgrid system. This paper demonstrates the multi-operations from a single stage transformerless voltage source inverter (VSI) in the ac-dc microgrid. The designed VSI coordinates active power from the Photovoltaic (PV) system, acts as a rectifier for the dc loads, performs VAR compensation as a static synchronous compensator (STATCOM) and reduces voltage and power oscillation as STATCOM/ESS (energy storage system) operation under divergent operating conditions, such as, sudden radiation changing, random load changing, different faults effects etc. The developed microgrid model represents the commercial smart microgrid built at Griffith University, Nathan campus, which consists of PV, battery energy storage system (BESS) and single stage transformer-less STATCOM. Performance analysis of the smart microgrid model is carried out in power system computer aided design (PSCAD) /electromagnetic transient de (EMTDC) software environment. The results prove that the designed VSI can coordinate individual power profiles distinctively maintaining system stability and the excess PV generated power contributes similarly as an ESS for STATCOM/ESS operations in the microgrid.
\end{abstract}

Index Terms - Smart microgrid, single stage transformer-less VSI, PV, STATCOM, STATCOM/ESS, PSCAD/EMTDC.

\section{INTRODUCTION}

The fossil fuel energy sources are the main energy supplier worldwide, however, the environmental issues with the conventional energy resources has led to the development and implementation of renewable energy sources, such as, solar, wind, hydropower, energy storage etc. in the supply network. The increasing number of the distribution generations (DGs) penetration in the electric power system and the electrical proximity among interconnected DGs in the network, has paved the way for the microgrid system. The incorporation of the renewable energy sources with advanced self-commutated flexible ac transmission system (FACST) devices and multipurpose storage medium has developed the concept of smart microgrid system. Compared to the bulk power utility systems, the smart microgrid contributes in bidirectional power flow and allows customers to participate in the electricity enterprise. Moreover, the existing microgrid can reduce the power transmission infrastructures related costs by fully supplying the required power demand on residential and commercial areas.

In conventional ac microgrid, multistage converters are used to supply the dc loads like Light emitting diode (LED) lights, electric vehicles (EVs) etc. and different ac loads. However, maintaining proper coordination control, ac and dc both powers can be supplied with less energy conversion stages from the two-bus microgrid system [1]. Among renewable energy systems, the proliferation of the PV system among customers is conspicuous due to special government incentives and trade in tariff offers. However, the increasing penetration depth of the nonlinear PV system in the distribution network has raised the concern of power quality and stability of the DG system. Unbalanced power supply and demand relationship is one of the reasons for the instability in a microgrid. Therefore, smooth power transfer between different conversion stages is ensured in the designed controller in this paper. Improper reactive power management is also responsible for the poor power quality and instability related issues. However, for a grid tied PV system, the IEEE 1547 standard requires unity power factor operation at the point of common coupling (PCC) [2]. Therefore, traditionally, FACTS devices are used in the bulk power systems for reactive power coordination operations, and STATCOM is the most widely used one. In recent years, with the increasing number of the DG units' penetration in the supply network, the feasibility of the reactive power from the DG units in the PCC point has been considered by the IEEE 1547.8 working group of SCC 21 [3] and also addressed in [4].

Voltage source inverter (VSI) is one of the key components in DG units and FACTS devices. The authors in [5] proposed and patented the renewable energy inverters, termed PVSTATCOM, to use as the active and reactive power controller at the PCC point. They implemented the controller in a real system with a poor power factor induction motor load and improved the power factor at the PCC point [6] [7]. 
Generally, during daytime, the PV system does not use the inverter's full capacity unless around midday when the sun radiation level is maximum. But, the inverter total $\mathrm{kVA}$ rating is chosen to handle more than the maximum peak capacity of the PV system. Hence, the remaining capacity of the inverter after active power conversion during the daytime and full capacity at the nighttime can be utilized for the reactive power management (STATCOM) related operation in the distribution network. Utilization of a separate ESS can make the microgrid to work in four-quadrant mode as a STATCOM/ESS system along with the active power and STATCOM operations. These concepts are demonstrated for the developed two-bus microgrid model in this paper, which has not been shown in [6] [7]. All day STATCOM/ESS operation with an additional ESS will be discussed on future papers, hence, in this paper, only during the PV system active condition, the designed VSI performs some features of the STATCOM/ESS operation like active power smoothing, oscillation damping etc.

The PV system with the active and reactive power profiles are addressed in several literatures [8-13]. However, these studies are mainly focused on the controller performance for ac loads in the supply network. The PV-STATCOM/ESS operations can be incorporated with both ac and dc loads to enhance the performance of the traditional microgrid system. Aforementioned operations for the designed VSI are analyzed under divergent operating conditions such as random radiation changing, symmetrical and asymmetrical faults application, abrupt ac and dc loads changing, PV source disconnection effects etc. using PSCAD/EMTDC software environment. The developed model is designed resembling the smart microgrid system in Griffith University, Nathan Campus (N44 building). The real system incorporates a $10 \mathrm{KW}$ solar PV, a $60 \mathrm{KWh}$ battery energy storage system (BESS) and a central single stage transformer-less 30 KVA STATCOM.

The rest of the paper is organized as follows: Section II describes briefly the modelling of the microgrid, section III shows different case studies and section IV concludes the paper with future works for the developed model.

\section{MODELLING}

The microgrid consists of three main sections-

i. $\quad$ DC bus :

a. Single stage PV system

b. Variable dc loads

ii. Central bidirectional VSI with LCL filter

iii. $\quad \mathrm{AC}$ bus :

a. Grid connection

b. Variable ac loads

The developed microgrid model is shown in Fig.1 (a). Fig. 1 (b) and Fig. 1 (c) (on last page) show the installed solar PV modules and control panel of the real system.

The DC bus consists of the PV system and variable dc loads. The PV generates maximum active power on the maximum power point (MPP) and transfers via the dc bus without any dc-dc conversion stages. The dc bus of the real system is regulated by the BESS. Therefore, a fixed reference value is considered for the dc bus in this paper instead from the MPPT controller. The dc loads are connected with a single-phase breaker (B_DC) to the dc bus. It receives power from the PV during $\mathrm{PV}$ active period and from the grid via bidirectional inverter when the PV is inactive.

A single stage transformer-less VSI is designed using IGBT switches with antiparallel diodes as a bidirectional inverter for the active and reactive power management operations in the microgrid. The dc link capacitor value is chosen considering $10 \% \mathrm{dc}$ ripple filtering and total KVA capacity of the inverter. It works as a ripple filter when the microgrid operates in the active power regime and energy storage $(\sim 5 \%)$ to compensate switching losses during reactive power operation. The dc bus voltage reference is calculated around $450 \mathrm{~V}$ considering some ripple voltage drop (10-20\%) in the VSI and the grid voltage value $(230 \mathrm{~V})$. However, a higher dc bus voltage $(600-800$ V) is preferred for PV-STATCOM operation as it helps to maintain system's stability in transition between full-capacity active and reactive power operations. The dc bus voltage is regulated using an outer voltage control loop following the dc voltage dynamic equation as shown below [14]

$$
\frac{1}{2} C \frac{d V_{d c}^{2}}{d t} \approx f\left(P V_{\text {array }}\right)-\frac{3}{2} v_{d} I_{d \_r e f}
$$

The VSI inner current control loops are designed considering the feed forward and decoupling functions as shown in Fig. 2. Here, the proportional-integral (PI) controller gain values and saturation limits on the current controller are defined in accordance to the performance of the developed model. Pulse width modulation (PWM) switching technique is used for the designed VSI operations. A phase locked loop (PLL) is used at the (PCC) point for grid synchronization and the synchronization angle is used in the synchronous reference frame transformations. The grid synchronization makes the PCC voltage $d$ axis component to follow the grid voltage vector and results voltage $q$ axis to follow zero. The dynamic active and reactive power for the PV can be written as [14],

$$
\begin{gathered}
P_{p c c}=\frac{3}{2}\left|v_{d}\right| I_{d} \\
Q_{p c c}=\frac{3}{2}\left|v_{d}\right| I_{q}
\end{gathered}
$$

The filter in the microgrid prevents harmonic contents of the inverter's output current and reduces total harmonic (THD) distortion at the PCC point. However, a poor filter design can introduce undesirable system instability. Therefore, in this paper, a LCL filter with a series damping resistor with the filter capacitor is properly designed considering power loss in the filter reactor [15]. The overall system dynamics can be simplified as,

$$
\left[\begin{array}{c}
v_{t d} \\
v t q
\end{array}\right]=R\left[\begin{array}{c}
I d \\
I q
\end{array}\right]+L \frac{d}{d t}\left[\begin{array}{c}
I d \\
I q
\end{array}\right]+L \omega\left[\begin{array}{c}
-I d \\
I q
\end{array}\right]+\left[\begin{array}{c}
v d \\
v q
\end{array}\right]
$$




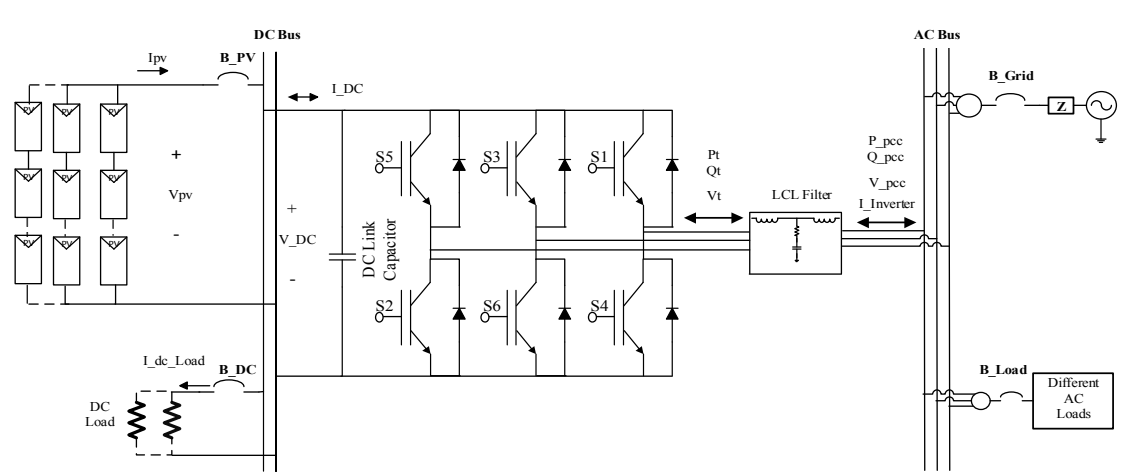

(a)

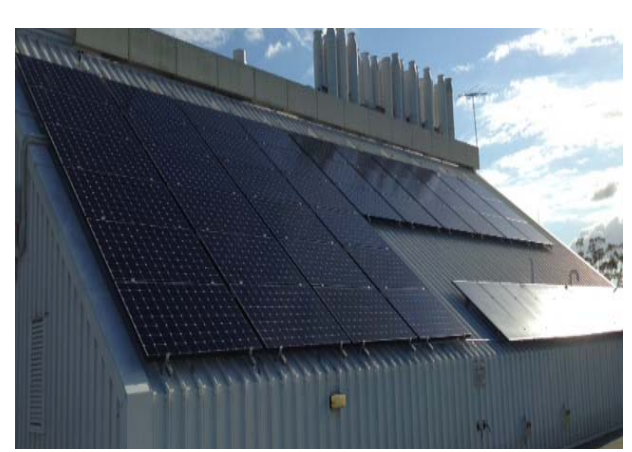

(b)

Fig. 1. (a) Developed microgrid model, and (b) installed solar modules of the real system at Griffith University, Nathan Campus

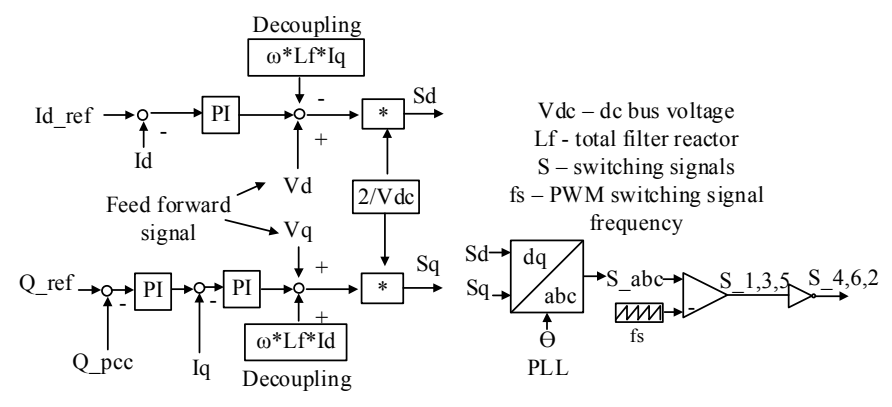

Fig. 2. Control diagram for the microgrid system

The ac bus consists of a stiff grid and variable ac loads. Thevenin's equivalent circuit with a three phase voltage source is considered as a stiff grid and different ac loads such as, three phase inductive, capacitive, resistive, static power and static impedance loads [17] are used in the microgrid model. The system ratings with parameter values are shown in the appendix.

\section{CASE STUDIES}

The case studies are performed for the designed VSI under abrupt operating conditions changing to analyze the performance of PV-STATCOM/ESS operations in the developed microgrid model. Under standard testing condition (STC), it is estimated that a single PV module generates around $650 \mathrm{~W}$. Total 10 parallel and 2 series modules are considered for the PV system and the maximum power capacity of the PV is around $13 \mathrm{~kW}$ at STC. The dc bus voltage reference is kept constant at $600 \mathrm{~V}$ and the grid voltage is $230 / 400 \mathrm{~V}$ at $50 \mathrm{~Hz}$ frequency. Dc loads are designed for $1.5 \mathrm{~kW}$ and $2 \mathrm{~kW}$ operations. Three phase passive linear (resistive $-8 \mathrm{~kW}$, inductive $-5 \mathrm{kVAR}$ and capacitive $-4 \mathrm{kVAR}$ ) and two static load models (constant power $-8 \mathrm{~kW}+\mathrm{j} 5 \mathrm{kVAR}$ and impedance $-6 \mathrm{~kW}+\mathrm{j} 3 \mathrm{kVAR}$ ) are used as ac loads. The studies demonstrate the operations of the designed VSI as an active power controller, STATCOM and STATCOM/ESS distinctively under divergent operating conditions. The active power operation ensures smooth power transfer according to load demand, STATCOM operation supports system VAR requirements and STATCOM/ESS provides power smoothing and oscillation damping operation in the microgrid as shown elaborately in the following case studies.

\section{A. Case study 1: PV with variable solar irradiance}

In practical PV system, atmospheric conditions change continuously and randomly. To evaluate the effect of atmospheric changes, irradiance level is changed from STC $1000 \mathrm{~Wb} / \mathrm{m}^{2}$ to maximum $1200 \mathrm{~Wb} / \mathrm{m}^{2}$ at $0.35 \mathrm{~s}$ and minimum $0 \mathrm{~Wb} / \mathrm{m}^{2}$ at $1.50 \mathrm{~s}$. Fig. 3. (a) shows the effect of the stochastic characteristic of the solar radiation. At $0.35 \mathrm{~s}$, the PV generates around $14.5 \mathrm{~kW}$, compensates the total load demand $(1.5 \mathrm{~kW} \mathrm{dc}$ and $6 \mathrm{~kW}+\mathrm{j} 3 \mathrm{kVAR}$ ac) and supplies the rest to the grid. At $1.50 \mathrm{~s}$, the radiation is changed from $1200 \mathrm{~Wb} / \mathrm{m}^{2}$ to around $0 \mathrm{~Wb} / \mathrm{m}^{2}$, which is shown in Fig. 3 (a) and 3 (b). However, despite the abrupt high irradiance differences and nonlinear sun irradiance characteristics, the developed VSI coordinates smooth power transfer in different stages without introducing any instability in the microgrid.

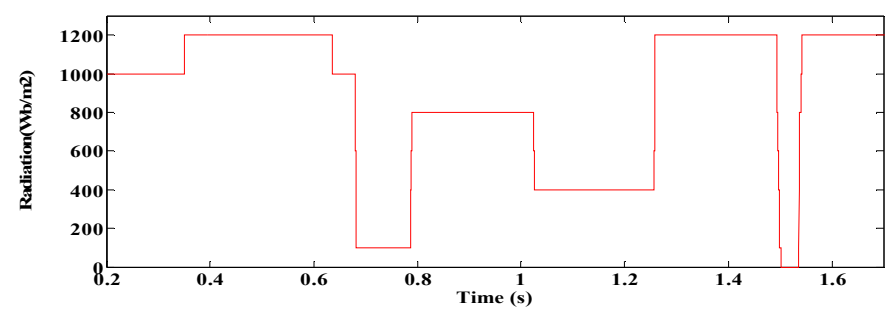

(a)

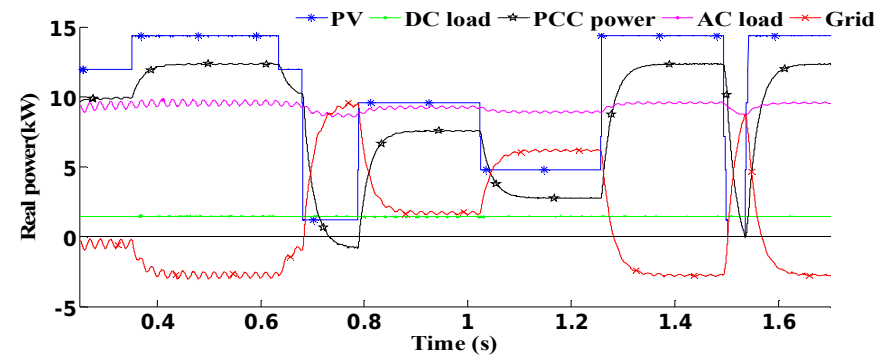

(b)

Fig. 3. Irradiance change effects: (a) radiation level changes, and (b) active power changes in the microgrid

\section{B. Case study 2: Dc bus reference change}

The dc bus voltage is regulated at a constant $600 \mathrm{~V}$ in this paper. However, in practical system, sun radiation changes randomly and so does the PV voltage. To analyze the adaptation of the designed controller in different operating 
environments and networks, variable dc voltage references are applied in the controller. During the case study, a $1.5 \mathrm{~kW} \mathrm{dc}$ load and $6 \mathrm{~kW}+\mathrm{j} 3 \mathrm{kVAR}$ static impedance ac load are kept connected with the system. The dc reference is randomly changed from $800 \mathrm{~V}$ to $500 \mathrm{~V}$ with and without the PV system connected to the dc bus. At $0.30 \mathrm{~s}$, the reference is suddenly dropped from $800 \mathrm{~V}$ to $500 \mathrm{~V}$, which introduces a large disturbance in the model, as can be seen from Fig. 4 (a) and Fig. 4 (b). In response to the disturbance, the PCC and grid power shows robust interaction to reduce the controller's overshoot effect. The PV system breaker is opened at $1.60 \mathrm{~s}$ and reference is again changed from $600 \mathrm{~V}$ to $800 \mathrm{~V}$ at $1.90 \mathrm{~s}$. During the PV system disconnected condition, the PV voltage reaches to the open circuit voltage $(900 \mathrm{~V})$ of the PV modules; however, the outer voltage controller makes the dc bus voltage to follow the reference accurately. It can be seen from the Fig. 4(a) and Fig. 4(b) that, without the PV source, large disturbances introduce oscillation in the output power. However, with the PV source, the oscillating effects are smoothened instantly, which shows the STATCOM/ESS operation of the design VSI controller. Connecting a separate BESS with the dc bus can make the system to work as STATCOM/BESS continuously even when the PV is inactive.

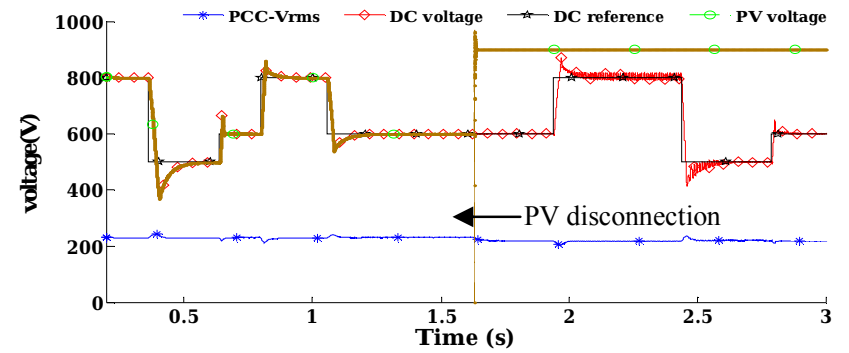

(a)

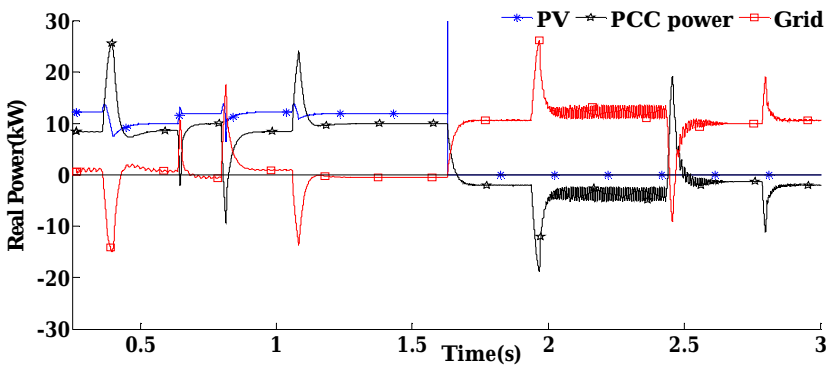

(b)

Fig. 4. Variable dc references: (a) voltage variations, and (b) active power variations in the microgrid

\section{Case study 3: Random ac loads changing}

The stability of a distribution system greatly depends on the connected loads characteristics. Abrupt changes in the sensitive loads can create undesirable system instability if not properly damped or compensated. This case study shows the effects of abrupt ac loads changing at the PCC. An $8 \mathrm{~kW}$ resistive load is kept connected from $0.60-2.30 \mathrm{~s}$ along with an inductive load (5 kVAR) from $1.10-1.50 \mathrm{~s}(8 \mathrm{~kW}+\mathrm{j} 5$ $\mathrm{kVAR})$ and capacitive load (4 kVAR) from $1.60-2.30 \mathrm{~s}(8$ $\mathrm{kW}-\mathrm{j} 4 \mathrm{kVAR}$ ). According to the load demand, the required active and reactive power is supplied by the PV system and the remaining power is transferred to the grid. The static impedance load ( $6 \mathrm{~kW}+\mathrm{j} 3 \mathrm{kVAR})$ is connected with the system from $2.50-2.90 \mathrm{~s}$ and static power load $(8 \mathrm{~kW}+\mathrm{j} 5$ $\mathrm{kVAR}$ ) from $3.10-4.0 \mathrm{~s}$. The dc load breaker is closed at 3.50s. Despite the divergent loads changing operation, the system maintains accurate demand and supply relationship in the microgrid as shown in Fig. 5(a). The oscillation in PCC and grid power is caused by the inductive load characteristics. However, the designed controller takes around $25-30 \mathrm{~ms}$ to damp the oscillation in reasonable limit for inductive loads, which shows the robust oscillation damping characteristics of the designed VSI controller. The phase relationship during load changing from inductive to capacitive is shown in Fig. 5(b). The result shows proper phase relationship between the PCC voltage and current despite the starting oscillation.

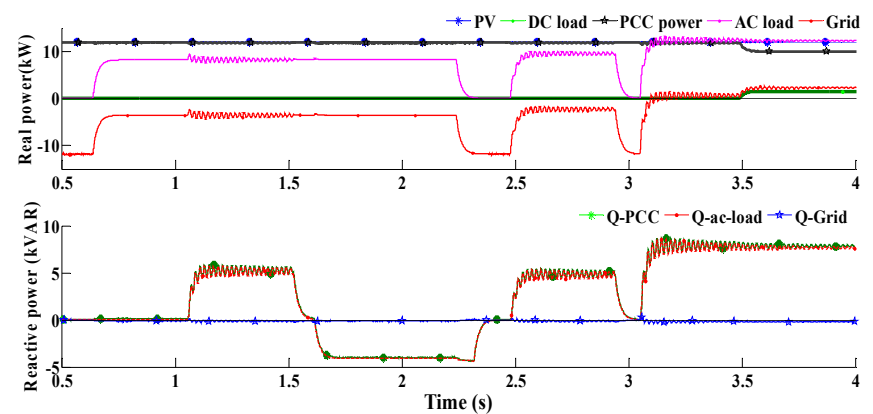

(a)
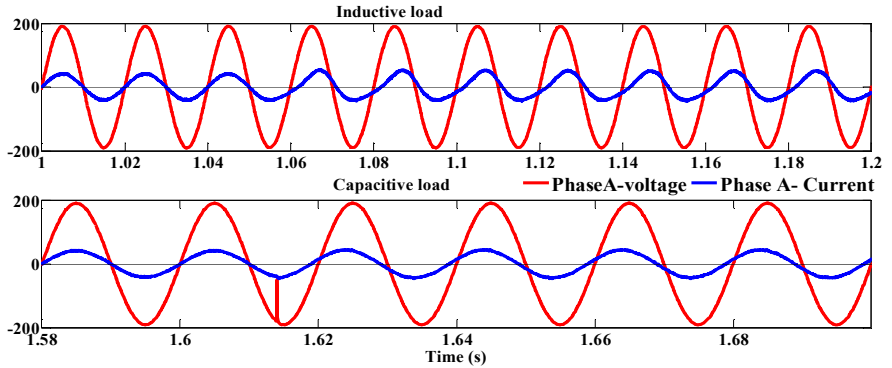

(b)

Fig. 5. Ac loads variation: (a) active and reactive power profiles, and (b) voltage and current phase during loads changing

\section{Case study 4: Symmetrical (3P-G) and asymmetrical (1P- $G)$ fault analysis with and without the PV system}

This study demonstrates the performance of the designed VSI as STATCOM and STATCOM/ESS under symmetrical (three phase to ground (3P-G)) and asymmetrical (single phase to ground (1P-G)) faults before and after the PCC point. A 2 $\mathrm{kW}$ dc and constant static impedance load $(6 \mathrm{~kW}+\mathrm{j} 3 \mathrm{kVAR})$ are kept connected during this study. The system is operated at STC with and without the PV system.

A three-phase to ground fault is considered as the most severe disturbance in the electric power system. Therefore, a 3P-G fault is applied before and after the PCC point at $0.35 \mathrm{~s}$ and $1.40 \mathrm{~s}$ for $0.20 \mathrm{~s}$. Fig. 6 (a) shows that, at the time of and after fault, the system exhibits robust stability recovery from oscillation. The PV system breaker is opened at $2.50 \mathrm{~s}$ and the same fault is applied again before PCC at $2.70 \mathrm{~s}$ and after PCC at $4.30 \mathrm{~s}$. The result shows that, the controller can damp fault oscillation more quickly while operating in STATCOM mode alone, which is expected as, the VSI is designed to work as a 
VAR compensator on full capacity to mitigate fault oscillation in absence of the PV system. Fig. 6(b) shows, despite the fault, the current remains limited with proper sinusoidal wave form.

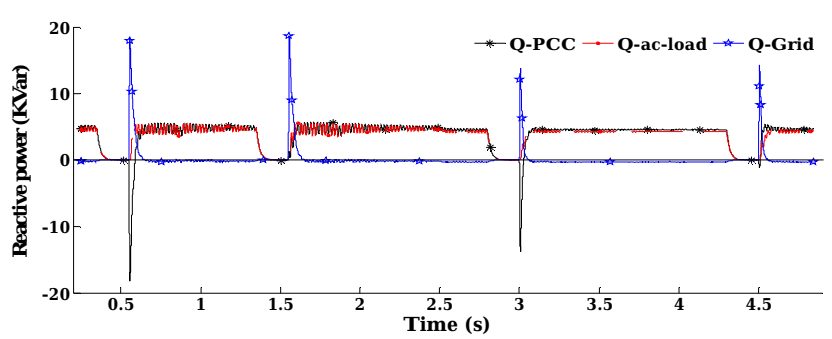

(a)

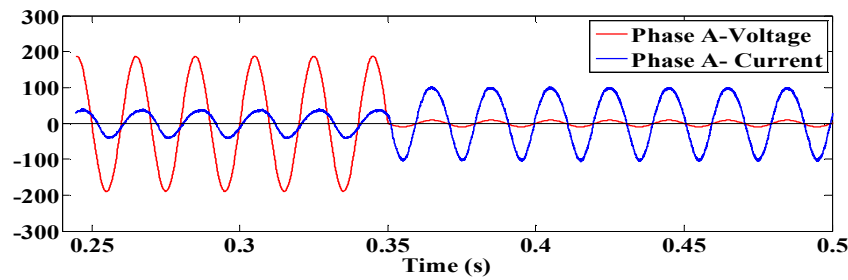

(b)

Fig. 6. 3P-G faults: (a) reactive power profile, and (b) voltage and current phase relation at PCC.

An asymmetrical fault, 1P-G (Phase B-G) fault, is applied same way as the symmetrical fault. In this case, the PV generated power remains immune to this fault and helps in robust recovery without any prior oscillation in the microgrid powers and voltages as can be seen from Fig. 7 (a) and Fig. 7 (b). The designed VSI response to 1P-G fault without the PV system shows rather little worse stability recovery effects than with the PV system. This is also expected, because the PV system works as a dc source in the microgrid and maintains stable dc bus voltage. Without the PV system, the dc bus becomes vulnerable to the faults as shown in the Fig. 7 (a) and 7 (b). This represents the concept that, when the PV system is active and generating more active power than system requirement, the remaining active power can be used for the STATCOM/ESS operation to damp system's oscillation.

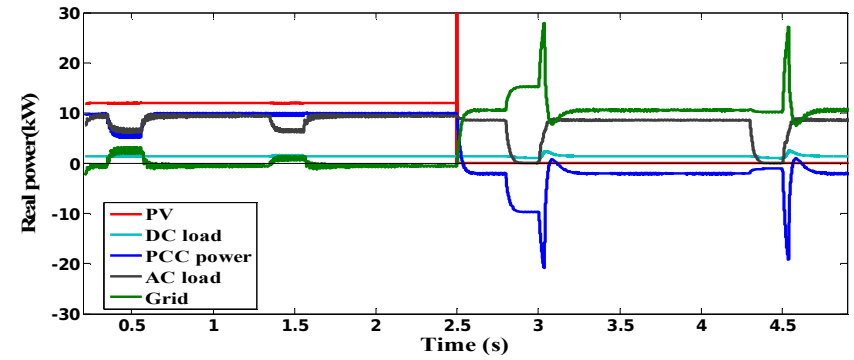

(a)

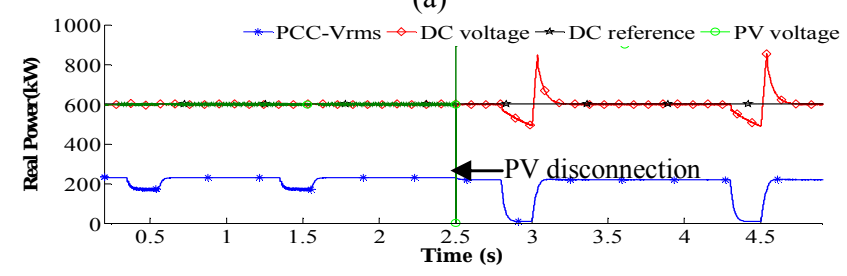

(b)

Fig. 7. 1P-G fault: (a) active power, and (b) voltage profiles

\section{E. Case study 5: PV disconnection and reconnection}

This study represents the effects on the VSI operation in absence of the PV system. The transition between full active and reactive operation modes requires smooth reference transfer in the controller without introducing any instability or time delay in the controller. To analyze this case, the PV breaker is kept open from $1.0-2.0 \mathrm{~s}$. During this time, the total active power demand is supplied by the grid (not shown), and the reactive power demand is supplied by the VSI as shown in Fig. 8 (a). Fig. 8 (b) shows, the system frequency remains constant at $50 \mathrm{~Hz}$ and the PCC current THD remains $\sim 3 \%$ despite the PV system connected and disconnected condition. The VSI full and partial capacity operation can be automatically organized by a fixed timed breaker operation or incorporating sun irradiance data to the breaker logic.

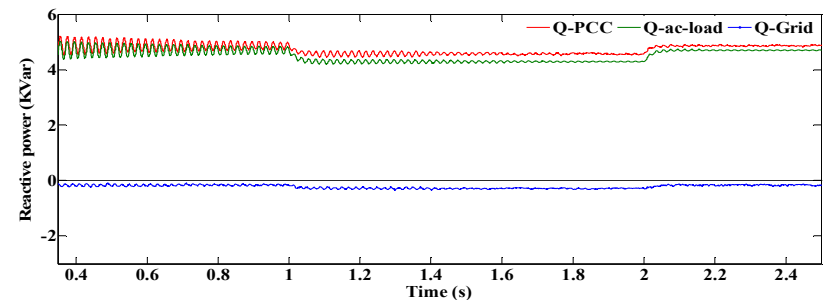

(a)
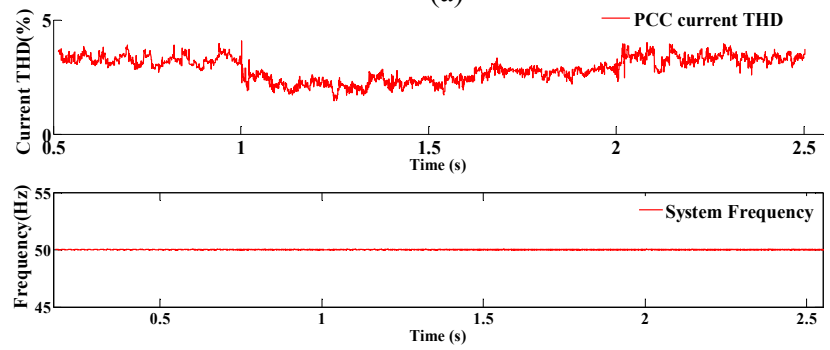

(b)

Fig. 8. PV disconnected operation: (a) reactive power, and (b) frequency and $\mathrm{I}_{\mathrm{PCC}_{-} \mathrm{THD}}$ of the microgrid

\section{F. Case study 6: Bidirectional VSI with variable dc loads:}

The bidirectional feature of the designed VSI is analyzed in this case study. A static impedance load $(6 \mathrm{~kW}+\mathrm{j} 3 \mathrm{kVAR})$ is kept connected to the ac bus. The dc load breaker is closed at $0.50 \mathrm{~s}$ and the load value is increased from $1.5-2.0 \mathrm{~kW}$ at $0.90 \mathrm{~s}$. During this time, the total $\mathrm{dc}$ and ac loads demand is supplied by the PV system. The PV breaker is kept open from $1.60 \mathrm{~s}-3.60 \mathrm{~s}$, and during this time the total active power demand is supplied by the grid. The VSI is designed to support certain amount $(0-2 \mathrm{~kW})$ of de load values and exceeding the limit, at $2.80 \mathrm{~s}$ to $3 \mathrm{~kW}$, results undesirable oscillation in the system as shown in Fig. 9 (a).

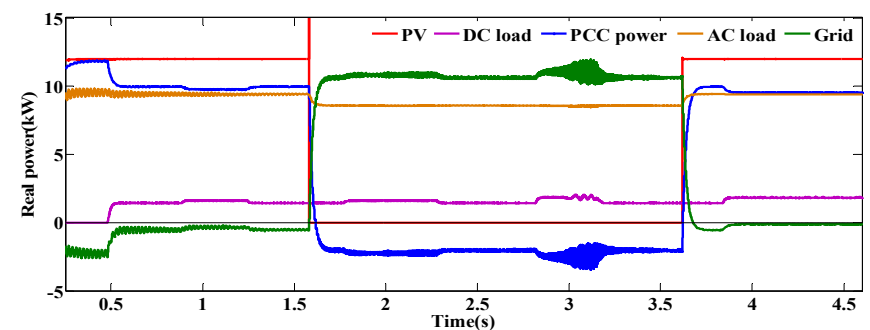

(a) 

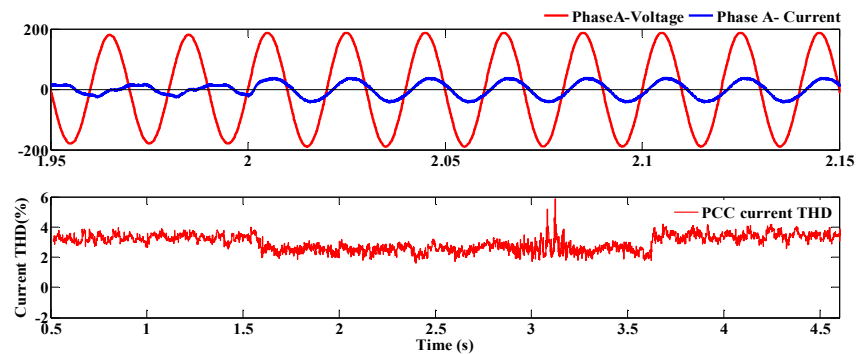

(b)

Fig. 9. Dc load variation (a) active powers, and (b) V\& I; I ICC _THD

Within the limit, the VSI is designed to works as a bidirectional converter to support the dc load demand maintaining proper voltage and current phase relation and THD $(\sim 3 \%)$ at the PCC as shown in Fig. 9 (b). This case study demonstrates the designed VSI operation for dc loads without any additional ac-dc or dc-dc conversion requirements.

\section{CONCLUSION}

The two-bus (dc and ac) microgrid system with designed single stage transformer-less VSI shows promising results for the active power, reactive power (STATCOM) and STATCOM/ESS operations. The VSI performs the operation of STATCOM/ESS function with the excess PV generated power despite the absence of a separate ESS in the developed microgrid model. However, the real microgrid system of Griffith University includes a BESS to operate with the VSI as STATCOM/BESS for 24 hours along with other features like peak load saving, load shifting etc. The microgrid shows proper coordination between system power demand and supply. Moreover, it ensures robust stability recovery under divergent operating conditions. The developed microgrid model with an additional BESS can potentially open up a new way of utilizing the PV microgrid for 24 hours operation in the electric power system with the possibility of earning extra revenues from the microgrid. The future work will emphasize on the controller overshoot effect reduction, STATCOM/BESS operation for 24 hours and feasibility checking of the designed model with the real commercial smart microgrid system at Griffith University.

\section{APPENDIX}

\begin{tabular}{|l|l|}
\hline Description & Specification \\
\hline PV module (PSCAD) & \\
\hline Series connected modules & 10 \\
\hline Parallel connected modules & 2 \\
\hline Cell in series connection & 108 \\
\hline Cell in parallel connection & 4 \\
\hline VSI & \\
\hline Inverter capacity & $20 \mathrm{kVA}$ \\
\hline Dc bus voltage & $600 \mathrm{~V}$ \\
\hline Dc link capacitor & $2000 \mu \mathrm{F}$ \\
\hline PI values & \\
\hline Dc voltage regulation & $\mathrm{Kp}=8 ; \mathrm{Ti}=0.005$ \\
\hline Inner current controller & $\mathrm{Kp}=5 ; \mathrm{Ti}=0.005$ \\
\hline LCL filter & \\
\hline Inverter side L & $4 \mathrm{mH}$ \\
\hline Grid side L & $1 \mathrm{mH}$ \\
\hline Filter capacitor & $10 \mu \mathrm{F}$ \\
\hline
\end{tabular}

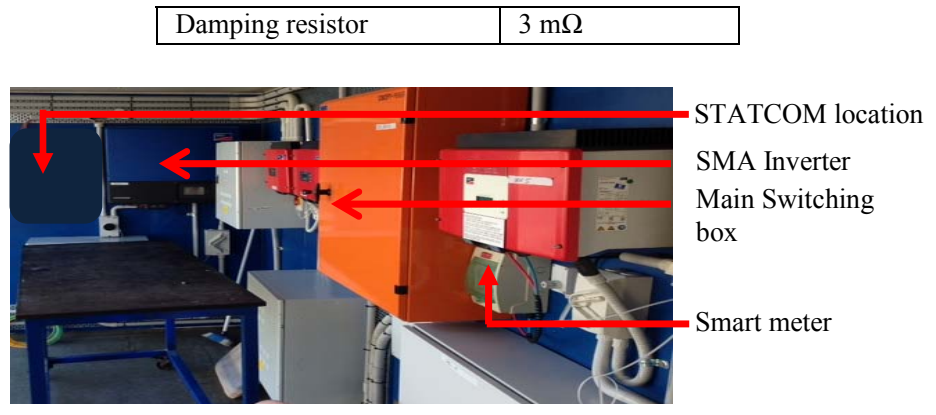

Fig. 1. (c) Controller panel of the active system

\section{REFERENCES}

[1] X. Liu, P. Wang, and P. C. Loh, "A hybrid AC/DC microgrid and its coordination control," IEEE Transactions on Smart Grid, vol. 2, no. 2, pp. 278-286, June, 2011.

[2] http://grouper.ieee.org/groups/scc21/1547/1547_index.html, IEEE 1547 Standard for Interconnecting Distributed Resources with Electric Power Systems.

[3] http://grouper.ieee.org/groups/scc21/1547.8/1547.8 index.html, IEEE P1547.8 Recommended Practice for Establishing Methods and Procedures that Provide Supplemental Support for Implementation Strategies for Expanded Use of IEEE Standard 1547.

[4] M. J. Hossain, M. A. Mahmud, H. R. Pota, and N. Mithulananthan, "Design of Non-Interacting Controllers for PV Systems in Distribution Networks," IEEE Transactions on Power Systems, issue 99, pp. 1-12, April, 2014.

[5] R. K. Varma, and V. Khadkikar, "Utilization of PV solar farm inverter as STATCOM," U.S patent, Sep. 15, 2009.

[6] R. K. Varma, S. S. Rangarajan, I. Axente, and V. Sharma, "Novel application of a PV solar plant as STATCOM during night and day in a distribution utility network," Power Systems Conference and Exposition, pp. $1-8$, March, 2011.

[7] R. K.Varma, E. M. Siavashi, B. Das, and V. Sharma, "Novel application of a PV solar plant as STATCOM (PV-STATCOM) during night and day in a distribution utility network: Part 2," IEEE PES Transmission and Distribution Conference and Exposition (T\&D), pp. 1-8, 2012.

[8] Z. Yang, C. Shen, L. Zhang, M. L. Crow, and S. Atcitty, "Integration of a StatCom and Battery Energy Storage," IEEE Transaction on Power System, vol. 16, no. 2, pp. 254-260, May, 2001.

[9] T. H. Kim, J. H. Lee, G. H. Kim, M. Park, and I. K. Yu, "Operation characteristic analysis of Three-phase grid connected PV system with AF and STATCOM," IEEE Vehicle Power and Propulsion Conference, pp. 1444 - 1448 ,October 2012, Seoul, Korea.

[10] A. Samadi, M. Ghandhari, and L. Soder, "Reactive power dynamics assessment of a PV system in a distribution grid," Energy Procedia, vol. 20, pp. 98-107, 2012.

[11] S. W. Lee, J. H. Kim, S. R. Lee, B. K. Lee, and C. Y. Won, "A tranformerless grid-connected photovoltaic system with active and reactive power control," IEEE 6th International Power Electronics and Motion Control Conference, pp. 2178-2181, 2009.

[12] H. Li, Y. Xu, S. Adhikari, D. T. Rizy, F. Li, and P. Irminger, "Real and reactive power control of a three phase single stage PV system and PV voltage stability," IEEE Power and Energy Society General Meeting, pp. $1-8,2012$.

[13] A. Yazdani, A. R. D. Fazio, H. Ghoddami, M. Russo, M. Kazerani, J. Jatskevich, K. Struz, S. Leva, and J. A. Martinez, "Modelling guidelines and a benchmark for power system simulation studies of three phase single stage photovoltaic system," IEEE Transactions on Power Delivery, vol. 26, issue 2, pp. 1247-1264, April, 2011.

[14] A. Yazdani, and R. Iravani, "Voltage-sourced converters: Modeling, control, and application," Hoboken, NJ: Wiley, 2010.

[15] A. Reznik, M. Godoy, A. A. Durra, and S. M. Muyeen, "LCL filter design and performance analysis for grid interconnected systems," IEEE Transactions on Industry Applications, vol. 50, no. 2, pp. 1225-1232, March/April, 2014.

[16] M.J. Hossain, T.K. Saha, N. Mithulananthan, and H.R. Pota, "Robust control strategy for PV system integration in distribution systems," Applied Energy, vol. 99, pp. 355-362, 2012.

[17] https://hvdc.ca/uploads/ck/files/...PSCAD_User_Guide_v4_3_1.pdf. 